\title{
Jurnal Algoritma
}

E-ISSN: 2302-7339 | P-ISSN: 1412-3622

INSTITUT TEKNOLOGI GARUT

\section{Perancangan Sistem Pendukung Keputusan Metode Simple Additive Weighting pada Pemilihan Merk Personal Komputer di Laboratorium PPL SMKN 1 Garut}

\author{
Andriansyah Maulana ${ }^{1}$, Sjahriani Datau ${ }^{2}$, Andi Nurfadillah $\mathrm{Ali}^{3}$ \\ Jurnal Algoritma \\ STMIK LIKMI \\ J1. Ir. H. Juanda No.96, Lebakgede, Kecamatan Coblong, Kota Bandung, Jawa Barat 40132 \\ Email : info@likmi.ac.id \\ ${ }^{1}$ andrimaulana105@gmail.com \\ 22sjahriani20@gmail.com \\ 3andinurfadillahali20@gmail.com
}

\begin{abstract}
Abstrak - Laboratorium kompetensi keahlian pengembangan perangkat lunak dan gim (PPL) merupakan laboratorium yang berada di bawah kompetensi keahlian pengembangan perangkat lunak dan gim (PPL) SMKN 1 Garut. Laboratorium PPL memiliki personal komputer (PC) sejumlah 40 PC, yang dilakukan rencana penambahan personal komputer atas usul dari ketua kompetensi pengembangan perangkat lunak dan gim dengan beberapa opsi merk personal komputer. Penelitian ini memakai model manajemen perancangan suatu metode Simple Additive Weighting (SAW) dengan memakai model-model yang digunakan sebagai pedoman untuk pengambilan keputusan antara lain harga, nilai ketahanan produk, nilai spesifikasi hardware dan nilai fleksibilitas produk. Penelitian ini menggunakan metode sistem pendukung keputusan yaitu Simple Additive Weighting dengan metodologi pengembangan sistem menggunakan metode prototyping. Hasil proses analisa berupa data personal komputer dari berbagai merk, dengan adanya sistem pendukung keputusan diharapkan dapat membantu ketua kompetensi keahlian pengembangan perangkat lunak dan gim dalam mengambil keputusan untuk memilih merk personal komputer yang terbaik untuk Laboratorium PPL SMKN 1 Garut.
\end{abstract}

Kata Kunci - Simple Additive Weighting; Sistem Pendukung Keputusan; SMKN 1 Garut.

\section{PENDAHULUAN}

Sistem Pendukung Keputusan merupakan bagian dari sebuah sistem informasi. Sistem informasi adalah jaringan kerja dari prosedur - prosedur yang saling berhubungan, berkumpul bersama sama untuk melakukan suatu kegiatan atau menyelesaikan suatu sasaran tertentu [1]. Menurut [2] sistem pendukung keputusan merupakan sistem informasi berbasis komputer yang mendapatkan cara alternatif keputusan dalam membantu manajemen untuk menangani berbagai permasalahan. Sistem pendukung keputusan berbasis komputer akan memberikan solusi dalam permasalahan dan akan membuat keputusan untuk lingkungan manajemen [3]. Sistem pendukung keputusan tidak dimaksudkan untuk mengotomatisasikan pengambilan keputusan tetapi memberikan perangkat interaktif yang memungkinkan pengambil keputusan untuk melakukan berbagai analisis [4].

Sistem Pendukung keputusan memiliki beberapa tujuan yaitu membantu pengambil keputusan untuk memecahkan masalah, mendukung penilaian pengambil keputusan dan meningkatkan efektifitas pengambil keputusan terhadap suatu permasalahan [5]. Kompetensi keahlian Pengembangan Perangkat Lunak dan Gim (PPL) saat ini memiliki 40 personal komputer (PC) yang digunakan untuk dua 
laboratorium PPL untuk mendukung aktivitas praktikum. Kompetensi keahlian pengembangan perangkat lunak dan gim (PPL) berencana menambah jumlah personal komputer untuk laboratorium PPL kompetensi keahlian pengembangan perangkat lunak dan gim, memerlukan suatu rancangan sistem pendukung keputusan agar dapat memilih merk personal komputer yang terbaik dari beberapa opsi merk personal komputer dengan menggunakan metode sistem pendukung keputusan yaitu Simple Additive Weighting dengan menggunakan metode pengembangan sistem prototype yang dapat mengurangi resiko seperti kemunculan error dan hal-hal yang terlewatkan dalam persyaratan [6]. Simple Additive Weighting (SAW) merupakan metode penjumlahan terbobot, konsep dasar metode SAW adalah mencari penjumlahan terbobot dari rating kinerja pada setiap alternatif pada semua kriteria [7]. Metode prototype merupakan metode pengembangan perangkat lunak, yang berupa model fisik kerja sistem dan berfungsi sebagai versi awal dari sistem [8], terdapat empat langkah dalam prototyping yaitu pengumpulan kebutuhan, proses desain yang cepat, membangun prototipe dan evaluasi serta perbaikan [9]. Sistem dengan model prototype memperbolehkan pengguna untuk mengetahui bagaimana sistem dapat berjalan dengan baik [10]. Menurut [11] kuncinya dalam pendekatan prototype adalah mendefinisikan aturanaturan main diawal.

Terdapat beberapa penelitian mengenai sistem pendukung keputusan yang dapat membantu pengambil keputusan dalam memecahkan suatu permasalahan, beberapa contoh penelitian sebelumnya adalah penelitian [3] yang bertujuan untuk mengambil keputusan terhadap permasalahan pemberian program bantuan langsung tunai di desa luwung bata untuk keluarga miskin yang berhak mendapatkan bantuan secara objektif dan tepat sasaran dengan menggunakan model manajemen sistem pendukung keputusan menggunakan metode Simple Additive Weighting (SAW) [12], penelitian selanjutnya mengenai demontrasi prosedur multi atribut decision making untuk memilih penerima beasiswa yang objektif pada beasiswa di Universitas Syiah Kuala [7]. Penelitian tersebut menjadi referensi untuk merancang sebuah sistem pendukung keputusan pemilihan merk personal komputer di laboratorium PPL SMKN 1 Garut dengan menggunakan metode Simple Additive Weighting (SAW) dengan metode pengembangan sistem yaitu prototype.

\section{METODE PENELITIAN}

Penelitian ini merancang sistem pendukung keputusan dengan metode Simple Additive Weighting untuk melakukan proses pemilihan merk personal komputer laboratorium pengembangan perangkat lunak dan gim dengan tujuan membantu pengambil kebijakan yaitu ketua kompetensi keahlian pengembangan perangkat lunak dan gim dalam memilih merk personal komputer untuk laboratorium pengembangan perangkat lunak dan gim. Adapun proses yang dilaksanakan untuk penelitian ini antara lain:

1) Analisis dan Evaluasi

Analisis dan evaluasi dilaksanakan dengan mengunjungi langsung objek penelitian, peneliti melaksanakan observasi, untuk menindaklanjuti masalah yang ada dan sedang dihadapi di objek penelitian yang dibutuhkan sebagai bahan studi pustaka untuk mengambil data - data yang dapat menunjang penelitian.

2) Pengumpulan data pendukung penelitian

Pengumpulan data pendukung penelitian dilakukan dengan mengumpulkan dokumen untuk acuan dalam penelitian, agar memperoleh data yang dibuat sebagai dasar untuk melaksanakan penelitian.

3) Perancangan Sistem

Sesudah didapatkan data pendukung penelitian, lalu perancangan sistem dengan model pendekatan berorientasi objek yaitu use case diagram.

4) Implementasi Dengan Rancangan antar muka Sistem

Setelah dilakukan tahap perancangan sistem, maka dilakukan implementasi dengan menggunakan desain interface sistem dengan metode pengembangan sistem menggunakan metode prototype. 
5) Penerapan metode SAW

Menerapkan metode SAW yang digunakan dalam melakukan seleksi pemilihan merk personal komputer yang diterapkan ke dalam rancangan sistem.

\section{HASIL DAN PEMBAHASAN}

\section{A. Perancangan Sistem}

Dalam penelitian ini dilaksanakan perancangan sistem dengan model pendekatan berorientasi objek dengan menggunakan use case diagram. Perancangan dibuat sesuai dengan sistem sehingga dalam pengambil keputusan dapat melaksanakan pemilihan merk personal komputer yang sesuai dengan penggunaan laboratorium pengembangan perangkat lunak dan gim SMKN 1 Garut dapat terpenuhi.

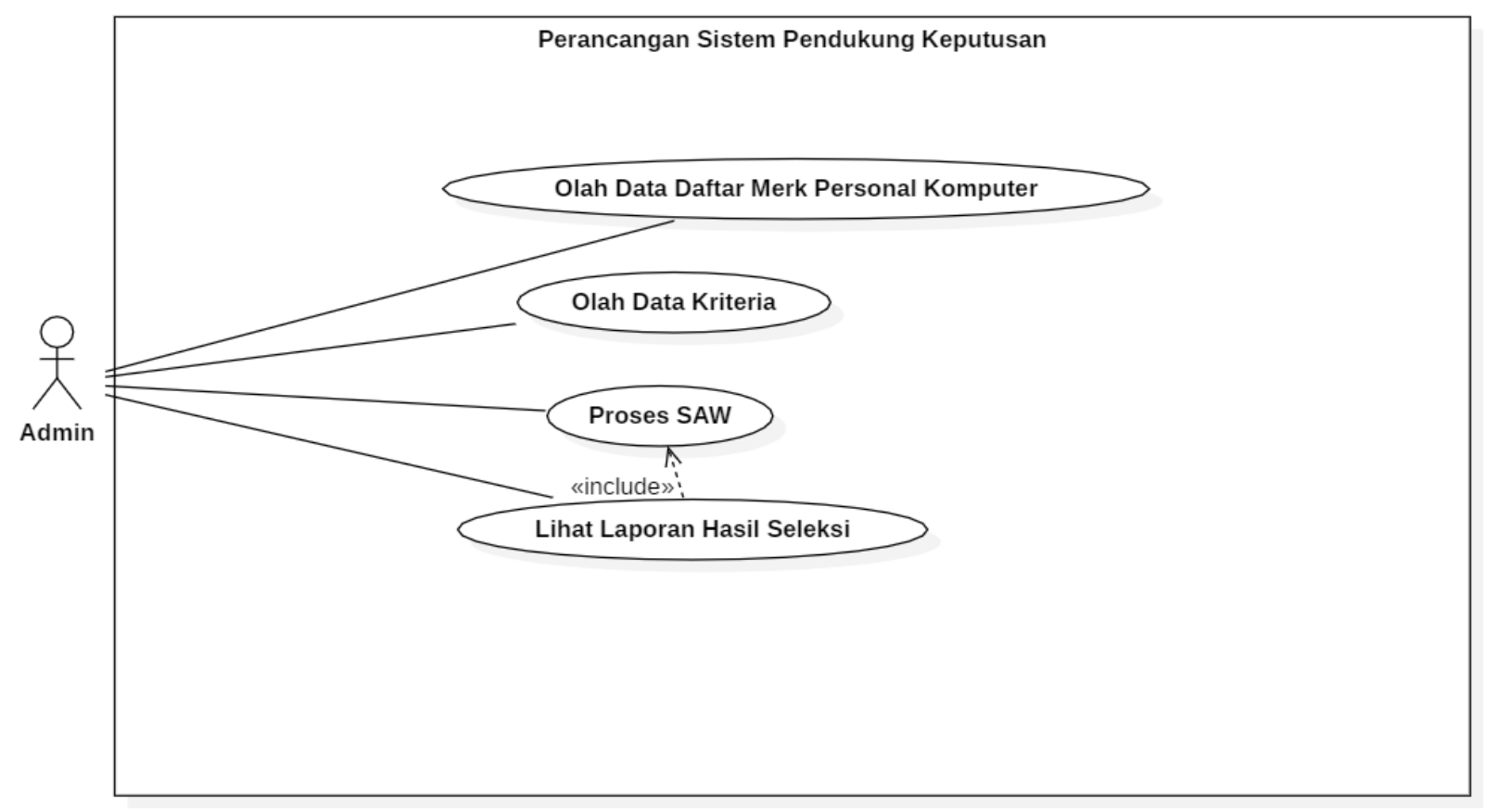

Gambar 2: Use Case Diagram Sistem

Pada Use Case Diagram tersebut mendeskripsikan sistem yang memiliki fungsionalitas untuk mengolah data daftar merk personal komputer yang tersedia, mengolah data kriteria yang ditentukan, proses seleksi SAW Dan setelah hasil seleksi didapat maka dapat melihat laporan hasil seleksi.

\section{B. Rancangan Antar Muka Sistem}

Implementasi sistem informasi merupakan suatu usaha dalam melaksanakan konstruksi sebuah sistem yang memberikan kepuasan akan spesifikasi kebutuhan fungsional. Hasil dari perancangan sistem pada penelitan ini adalah penerapan dengan desain interface sistem untuk pengguna. Berikut desain antar muka pengguna pada penelitian ini: 


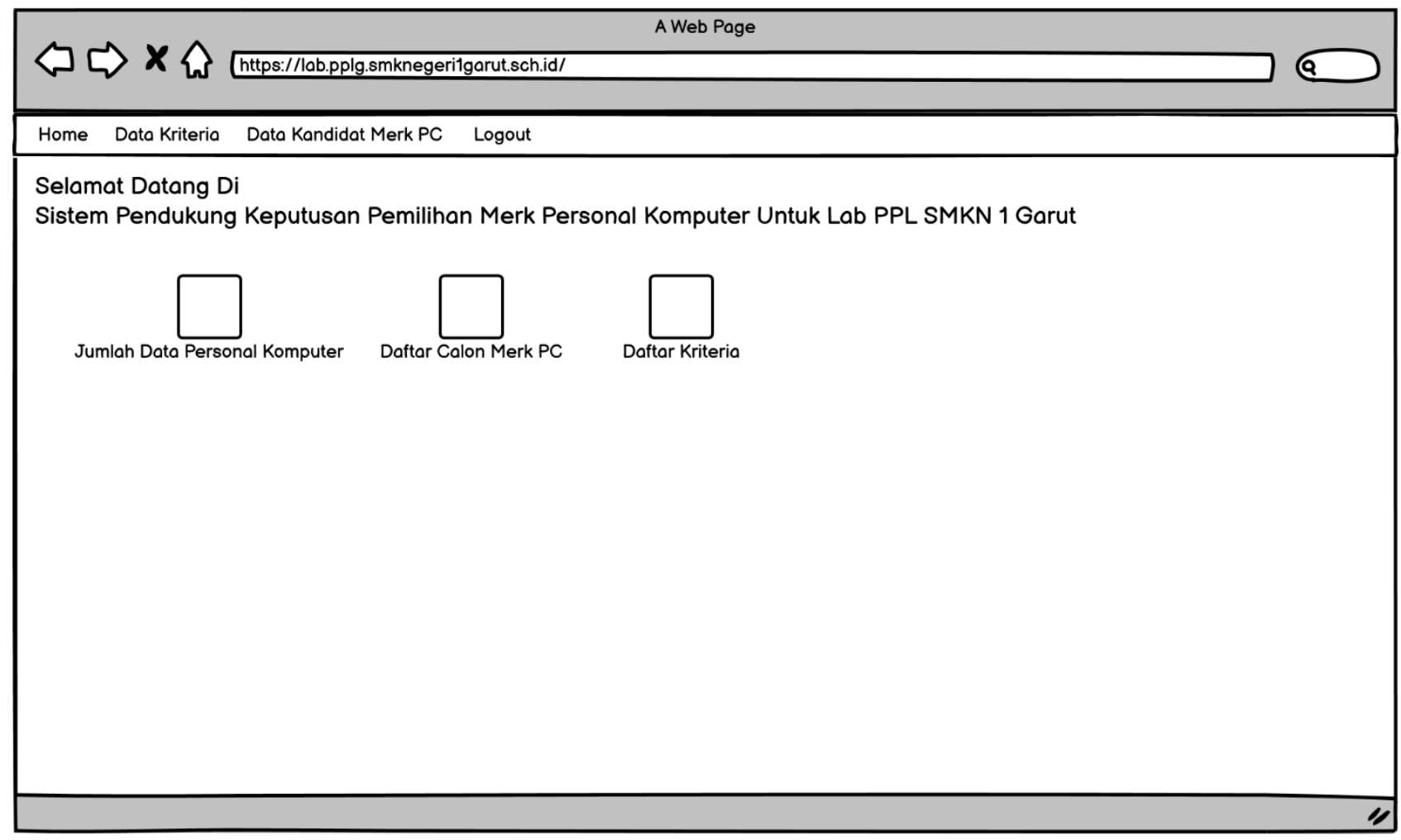

Gambar 3: Desain Halaman Home

Pada desain halaman home menampilkan antar muka jumlah data jumlah personal komputer, data calon merk PC yang akan digunakan dan daftar kriteria.

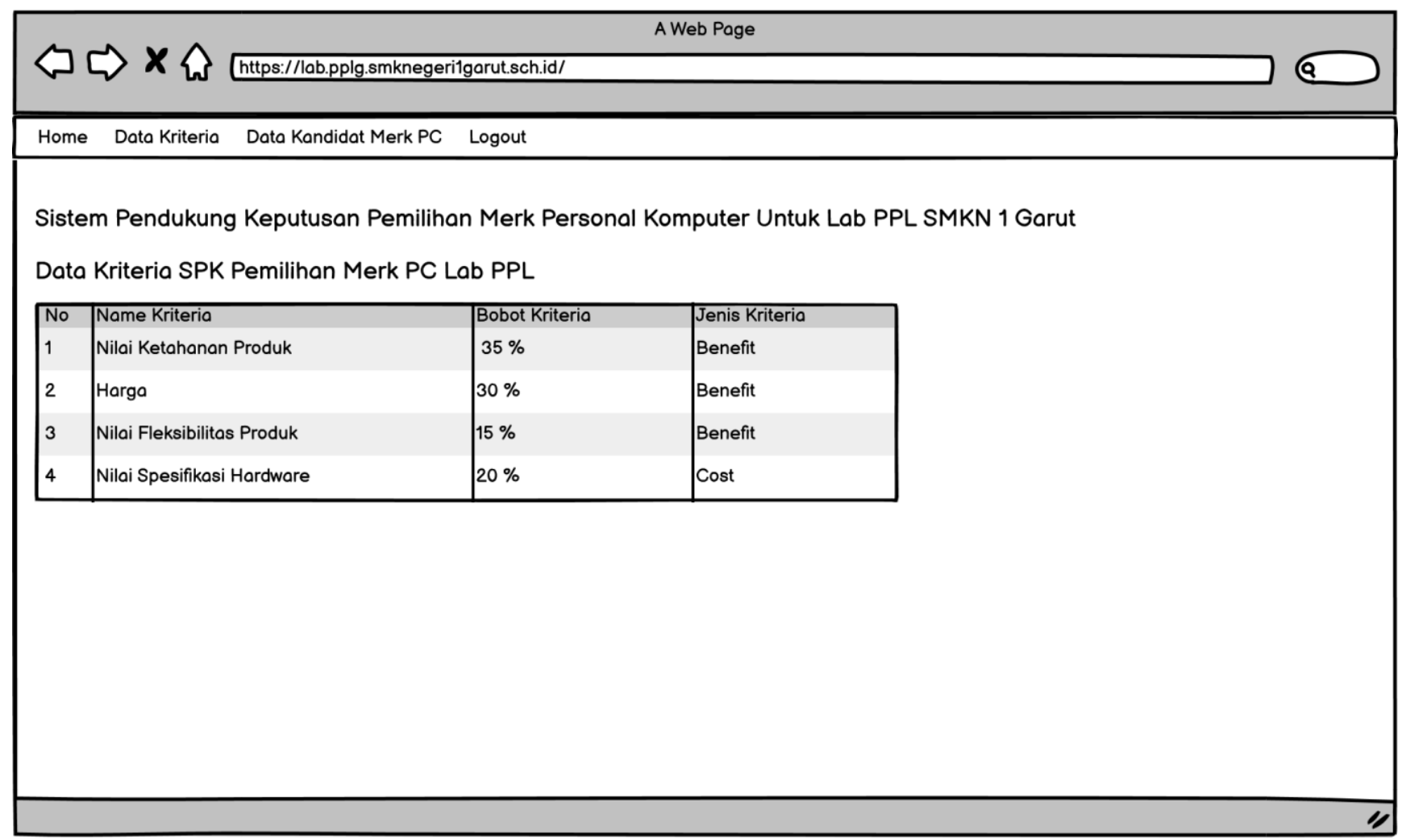

Gambar 4: Data Kriteria SPK Pemilihan Merk Personal Komputer Lab PPL 
Pada desain data kriteria merk personal komputer menampilkan antar muka data kriteria yang digunakan, beserta bobot kriteria dan jenis kriteria.

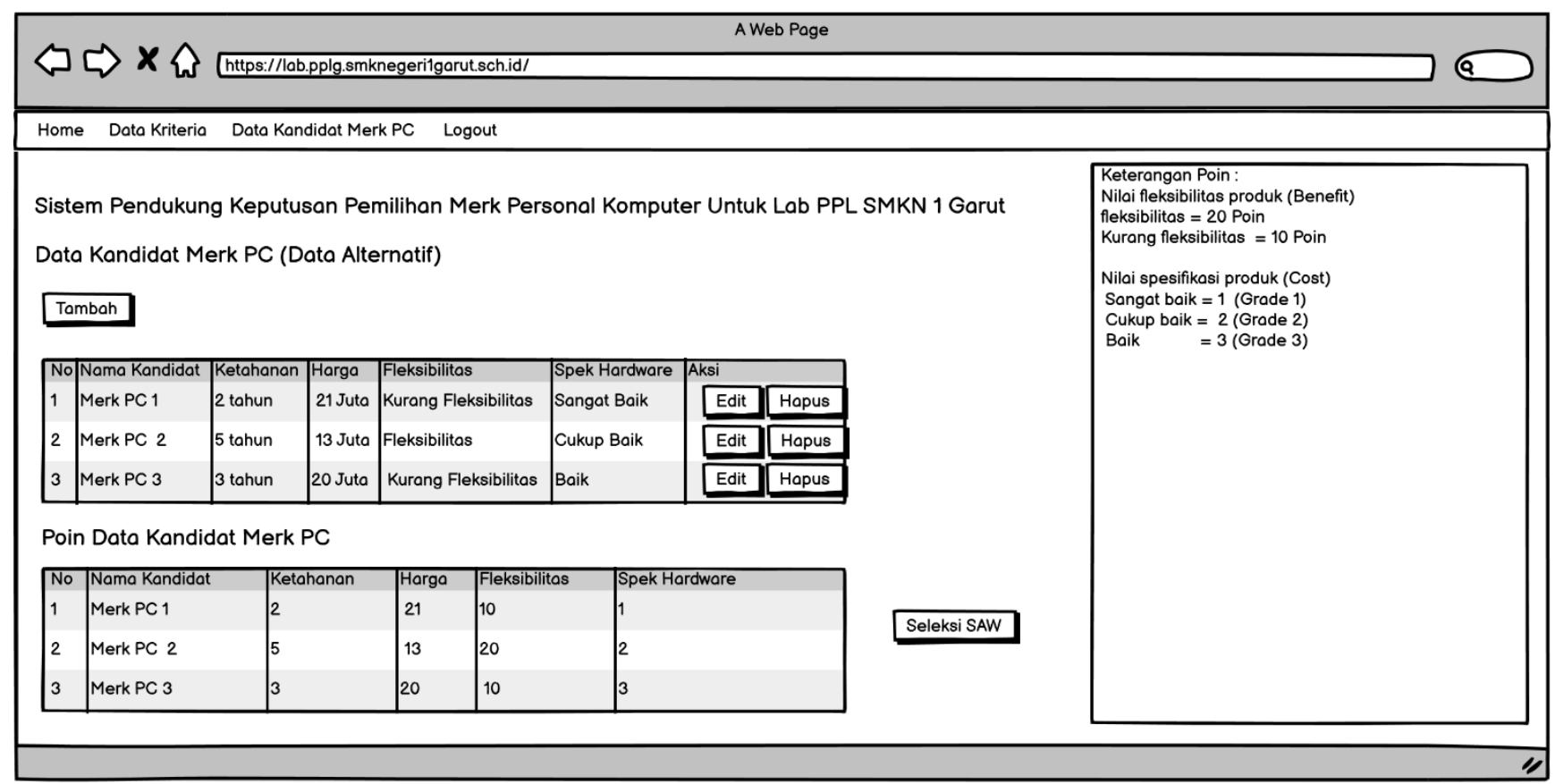

Gambar 5: Data Kandidat Merk Personal Komputer Lab PPL

Pada desain data kandidat merk personal komputer menampilkan antar muka data kandidat merk PC beserta poin data kandidat terhadap berbagai kriteria yang akan digunakan untuk proses seleksi.

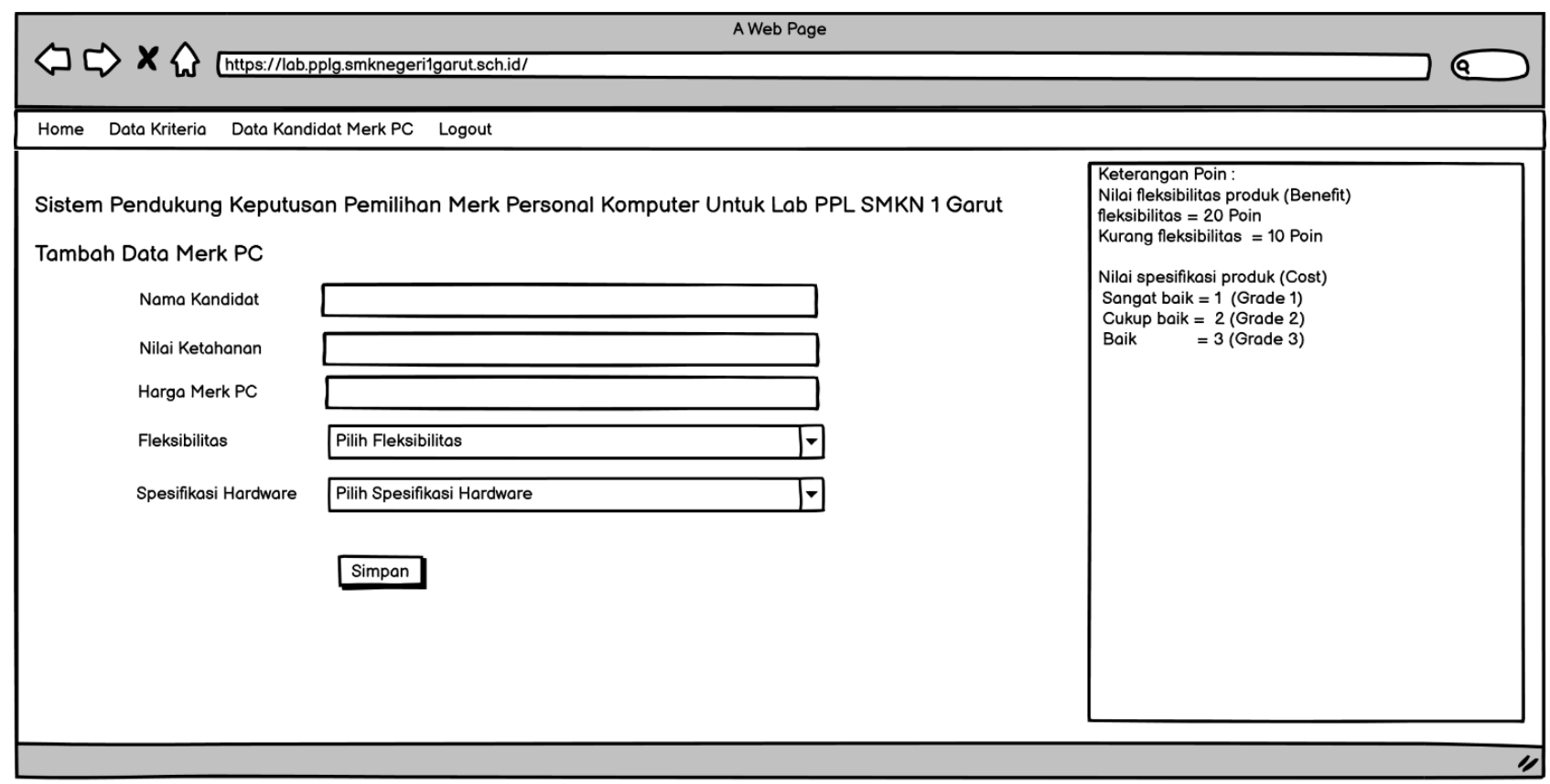

Gambar 6: Formulir Tambahan Data Merk Personal Komputer

Pada desain form tambah data merk personal komputer menampilkan antar muka formulir data merk PC terhadap kriteria - kriteria yang akan digunakan, serta ditampilkan informasi keterangan poin dari kriteria. 


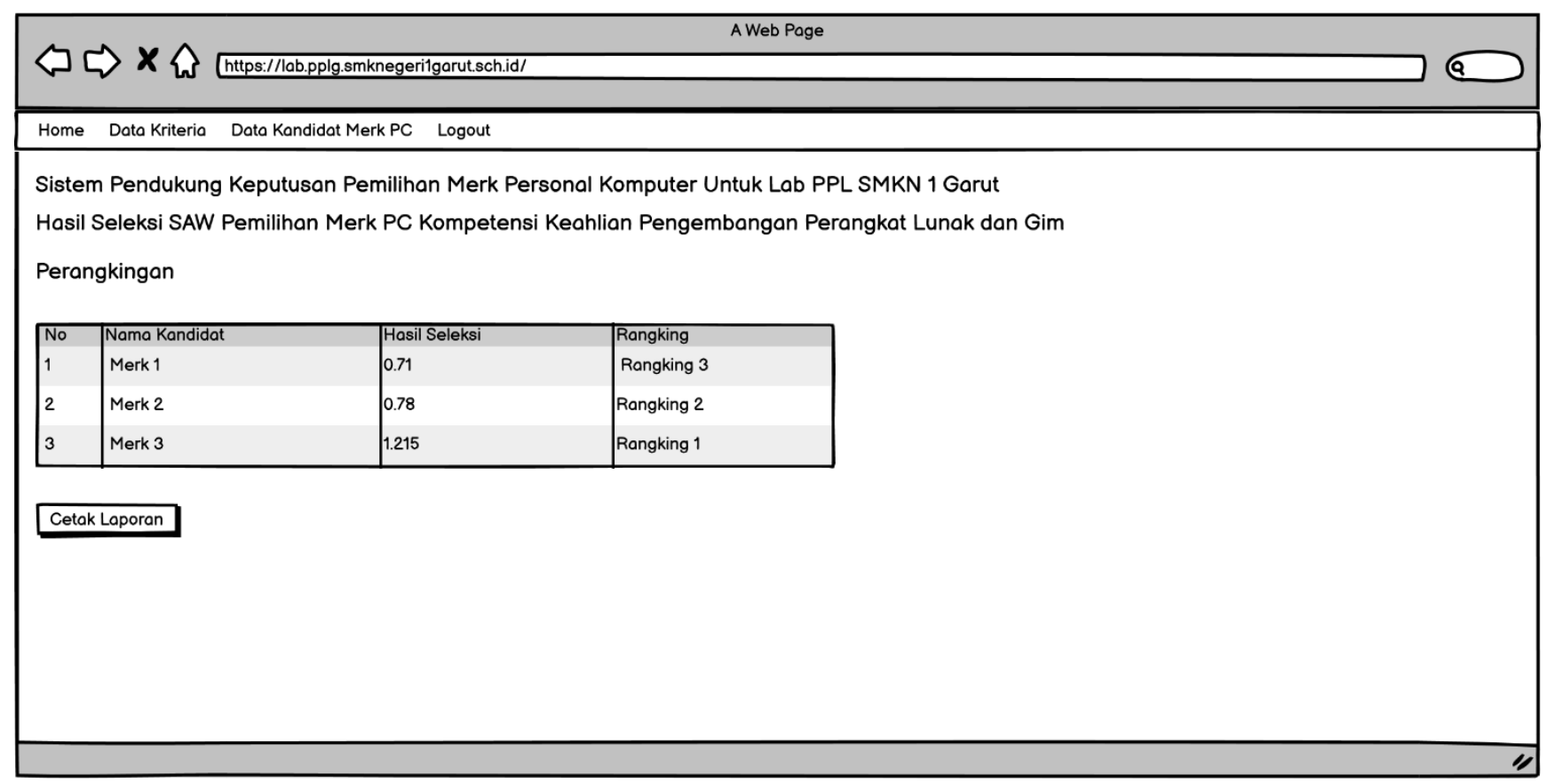

Gambar 7: Hasil Seleksi SAW Merk PC Lab PPL

Pada desain antar muka data hasil seleksi SAW merk personal komputer ditampilkan perangkingan hasil seleksi setelah pada halaman data kandidat merk personal komputer lab PPL (Gambar 5) ditekan button seleksi SAW.

\section{Penerapan Metode Simple Additive Weighting (SAW)}

Metode Simple Additive Weighting menerapkan proses normalisasi matriks keputusan terhadap suatu skala yang dapat dibandingkan dengan semua rating alternatif yang ada. Dibutuhkan data yaitu pilihan keputusan, syarat ketentuan dan bobot keputusan yang memodifikasi dalam pendukung keputusan dalam pemilihan merk personal komputer laboratorium pengembangan perangkat lunak dan gim

Berikut adalah kriteria dan bobotnya:

Tabel 1: Kriteria pemilihan merk personal komputer

\begin{tabular}{clcc}
\hline No & \multicolumn{1}{c}{ Kriteria } & Bobot (\%) & Jenis Kriteri \\
\hline 1 & Nilai Ketahanan Produk & 35 & Benefit \\
\hline 2 & Harga & 30 & Cost \\
\hline 3 & Nilai Fleksibilitas Produk & 15 & Benefit \\
\hline 4 & Nilai Spesifikasi Hardware & 20 & Cost \\
\hline
\end{tabular}

Berikut merupakan sample alternatif terhadap kriteria

Tabel 2: Alternatif merk personal komputer

\begin{tabular}{ccccc}
\hline $\begin{array}{c}\text { Nama } \\
\text { Kandidat }\end{array}$ & $\begin{array}{c}\text { Nilai Ketahanan } \\
\text { (Dalam Tahun) }\end{array}$ & $\begin{array}{c}\text { Harga (Dalam } \\
\text { Juta) }\end{array}$ & $\begin{array}{c}\text { Nilai Fleksibilitas } \\
\text { Produk }\end{array}$ & $\begin{array}{c}\text { Nilai Spesifikasi } \\
\text { Hardware }\end{array}$ \\
\hline Merk PC 1 & 2 tahun & 21 Juta & Kurang Fleksibilitas & Sangat Baik \\
\hline Merk PC 2 & 5 tahun & 13 Juta & Fleksibilitas & Cukup Baik \\
\hline Merk PC 3 & 3 tahun & 20 Juta & Kurang Fleksibilitas & Baik \\
\hline
\end{tabular}


Nilai spesifikasi produk (Cost)

Sangat baik $=1($ Grade 1$)$

Cukup baik $=2($ Grade 2$)$

Baik $=3($ Grade 3$)$

Tabel 3: Alternatif Terhadap Kriteria

\begin{tabular}{ccccc}
\hline Nama Kandidat & $\begin{array}{c}\text { Nilai Ketahanan } \\
\text { (Dalam Tahun) }\end{array}$ & $\begin{array}{c}\text { Harga (Dalam } \\
\text { Juta) }\end{array}$ & $\begin{array}{c}\text { Nilai Fleksibilitas } \\
\text { Produk }\end{array}$ & $\begin{array}{c}\text { Nilai Spesifikasi } \\
\text { Hardware }\end{array}$ \\
\hline Merk PC 1 & 2 & 21 & 10 & 1 \\
\hline Merk PC 2 & 5 & 13 & 20 & 2 \\
\hline Merk PC 3 & 3 & 20 & 10 & 3 \\
\hline
\end{tabular}

Untuk kriteria benefit menggunakan rumus:

$$
\mathrm{r}_{\mathrm{ij}}=\frac{x_{i j}}{\operatorname{Max} x_{i j}}
$$

Untuk kriteria cost menggunakan rumus :

$$
\mathrm{r}_{\mathrm{ij}}=\frac{\operatorname{Min} x_{i j}}{x_{i j}}
$$

Nilai ketahanan produk (C1)

Merk PC 1:

$$
r_{11}=\frac{2}{\operatorname{Max}(2,5,3)}=2 / 5=0.4
$$

Merk PC 2:

$$
r_{21}=\frac{5}{\operatorname{Max}(2,5,3)}=5 / 5=1
$$

Merk PC 3:

$$
r_{31}=\frac{3}{\operatorname{Max}(2,5,3)}=3 / 5=0.6
$$




\section{Harga (C2)}

\section{Merk PC 1:}

$r_{12}=\frac{\operatorname{Min}(21,13,20)}{21}=13 / 21=0.61$

Merk PC 2:

$$
r_{22}=\frac{\operatorname{Min}(21,13,20)}{13}=13 / 13=1
$$

Merk PC 3:

$$
r_{32}=\frac{\operatorname{Min}(21,13,20)}{20}=13 / 20=0.65
$$

Nilai Fleksibilitas Produk (C3)

\section{Merk PC 1:}

$r_{13}=\frac{10}{\operatorname{Max}(10,20,10)}=10 / 20=0.5$

\section{Merk PC 2:}

$$
r_{23}=\frac{20}{\operatorname{Max}(10,20,10)}=20 / 20=1
$$

Merk PC 3:

$$
r_{33}=\frac{10}{\operatorname{Max}(10,20,10)}=10 / 20=0.5
$$

Nilai spesifikasi hardware (C4)

Merk PC 1

Merk PC 2 :

$$
r_{14}=\frac{M n(1,2,3)}{1}=1 / 1=1
$$

Merk PC 3 :

$$
r_{24}=\frac{M n(1,2,3)}{2}=1 / 2=0.5
$$

$$
r_{34}=\frac{M n(1,2,3)}{3}=1 / 3=0.33
$$


Berikut merupakan hasil dari matriks normalisasi berdasarkan perhitungan diatas.

Tabel 4: Matrik Normalisasi

\begin{tabular}{ccccc}
\hline Nama Kandidat & $\begin{array}{c}\text { Nilai Ketahanan } \\
(\text { C1) }\end{array}$ & Harga (C2) & $\begin{array}{c}\text { Nilai Fleksibilitas } \\
\text { Produk (C3) }\end{array}$ & $\begin{array}{c}\text { Nilai Spesifikasi } \\
\text { Hardware (C4) }\end{array}$ \\
\hline Merk PC 1 & 0.4 & 0.61 & 0.5 & 1 \\
\hline Merk PC 2 & 1 & 1 & 1 & 0.5 \\
\hline Merk PC 3 & 0.6 & 0.65 & 0.5 & 0.33 \\
\hline
\end{tabular}

Berikut merupakan data bobot dari setiap kriteria

Tabel 5: Data bobot dari setiap kriteria (W)

\begin{tabular}{cccc}
\hline No & Kriteria & Bobot $(\%)$ & Jenis Kriteri \\
\hline 1 & Nilai Ketahanan Produk & $0.35\left(\mathrm{~W}_{1}\right)$ & Benefit \\
\hline 2 & Harga & $0.3\left(\mathrm{~W}_{2}\right)$ & Cost \\
\hline 3 & Nilai Fleksibilitas Produk & $0.15\left(\mathrm{~W}_{3}\right)$ & Benefit \\
\hline 4 & Nilai Spesifikasi Hardware & $0.2\left(\mathrm{~W}_{4}\right)$ & Cost \\
\hline
\end{tabular}

Menghitung Vector Bobot dan Perangkingan

Menghitung Vector Bobot menggunakan rumus :

$V_{i}=\sum_{j=1}^{n} W_{j} r_{i j}$

Keterangan Rumus :

$\mathrm{VI}=$ Nilai bobot preferensi dari setiap alternatif $\mathrm{Wj}=$ Nilai bobot kriteria rij = Nilai rating kinerja

Menghitung nilai bobot preferensi setiap alternatif

Merk PC 1 :

$V_{i}=\left(\mathrm{W}_{1} \times \mathrm{r} 11\right)+\left(\mathrm{W}_{2} \times \mathrm{r} 12\right)+\left(\mathrm{W}_{3} \times \mathrm{r} 13\right)+\left(\mathrm{W}_{4} \times \mathrm{r} 14\right)$

$=(0.35 \times 0.4)+(0.3 \times 0.61)+(0.15 \times 0.5)+(0.2 \times 1)$

$=0.14+0.183+0.075+0.2$

$=0,598$

Merk PC 2 :

$V_{i}=\left(\mathrm{W}_{1} \times \mathrm{r} 21\right)+\left(\mathrm{W}_{2} \times \mathrm{r} 22\right)+\left(\mathrm{W}_{3} \times \mathrm{r} 23\right)+\left(\mathrm{W}_{4} \times \mathrm{r} 24\right)$

$=(0.35 \times 1)+(0.3 \times 1)+(0.15 \times 1)+(0.2 \times 0.5)$

$=0.35+0.3+0.15+0.1$

$=0,9$

Merk PC 3 :

$V_{i} \quad=\left(\mathrm{W}_{1} \times \mathrm{r} 31\right)+\left(\mathrm{W}_{2} \times \mathrm{r} 32\right)+\left(\mathrm{W}_{3} \times \mathrm{r} 33\right)+\left(\mathrm{W}_{4} \times \mathrm{r} 34\right)$

$=(0.35 \times 0.6)+(0.3 \times 0.65)+(0.15 \times 0.5)+(0.2 \times 0.33)$

$=0.21+0.195+0.075+0.66$

$=1,14$ 
Perangkingan

Tabel 6: Hasil Perangkingan SAW

\begin{tabular}{cccc}
\hline No & Nama Alternatif & Hasil & Jenis Kriteri \\
\hline 1 & Merk PC 1 & 0.598 & Rangking 3 \\
\hline 2 & Merk PC 2 & 0.9 & Rangking 2 \\
\hline 3 & Merk PC 3 & 1.14 & Rangking 1 (Terpilih) \\
\hline
\end{tabular}

Berdasarkan hasil seleksi merk personal komputer (PC) untuk kebutuhan laboratorium pengembangan perangkat lunak dan gim pada kompetensi keahlian pengembangan perangkat lunak dan gim maka merk pc 3 yang terpilih menjadi merk personal komputer (PC) yang dapat dipilih oleh ketua kompetensi keahlian pengembangan perangkat lunak dan gim SMKN 1 Garut.

\section{KESIMPULAN}

\section{A. Kesimpulan}

Kesimpulan dari penelitian tentang pemilihan merk personal komputer yang sesuai dengan kebutuhan lab pengembangan perangkat lunak dan gim SMKN 1 Garut menggunakan perancangan sistem Pendukung Keputusan metode Simple Additive Weighting (SAW) adalah sebagai berikut:

1. Rancangan sistem pendukung keputusan dengan metode Simple Additive Weighting dapat memudahkan pengambilan keputusan untuk pemilihan merk personal komputer lab pengembangan perangkat lunak dan gim di SMKN 1 Garut.

2. Metode Simple Additive Weighting dapat memudahkan pemilihan merk personal komputer dengan menggunakan kriteria dan bobot yang ditentukan.

3. Hasil dari penelitian ini adalah rancangan sistem pendukung keputusan tentang pemilihan merk personal komputer di lab pengembangan perangkat lunak dan gim SMKN 1 Garut yang membantu pengembang sistem untuk melakukan pembangunan sistem pendukung keputusan dan dapat memudahkan pengambil keputusan dalam memilih merk personal komputer.

\section{B. Saran}

Penelitian berikutnya diharapkan dapat menerapkan rancangan sistem pendukung keputusan menjadi sebuah aplikasi sistem pendukung keputusan berbasis web maupun berbasis perangkat bergerak agar sistem dapat diakses oleh pengambil keputusan.

\section{UCAPAN TERIMA KASIH}

Penulis mengucapkan Terima Kasih kepada Ketua Kompetensi Pengembangan Perangkat Lunak dan gim SMKN 1 Garut yang telah mengizinkan penulis untuk melakukan penelitian ini, dan penulis juga mengucapkan Terima Kasih untuk Civitas akademik Institut Teknologi Garut yang telah memperbolehkan menulis jurnal di jurnal algoritma Institut Teknologi Garut.

\section{DAFTAR PUSTAKA}

[1] A. Kristanto, "Perancangan Sistem Informasi dan Aplikasinya (Edisi Revisi)," Gava Media, 2018.

[2] I. S. Budi and M. Syahrizal, "Decision Support System In Sous Chef De Partie Selection Using Simple Method Additive Weighting (SAW)(Case Study: Restaurant Goela Batoe)," IJICS (International ..., 
2019.

[3] R. Astuti and U. Mukaromah, "Model Manajemen Sistem Pendukung Keputusan Metode Simple Additive Weighting untuk Program Bantuan Langsung Tunai di Desa Luwungbata," Media Inform., 2021, doi: 10.37595/mediainfo.v19i3.47.

[4] Kusrini, "Konsep Dan Aplikasi Sistem Pendukung Keputusan,” Penerbit Andi. 2007.

[5] P. Purwadi, W. R. Maya, and A. Calam, "Sistem Pendukung Keputusan Untuk Menentukan Pemasangan Lokasi Strategis Wifi.Id Pada Telkom (Studi Kasus Pada Pemsangan Wifi.Id Di Beberapa Lokasi Medan Menggunakan Metode Oreste," J. SAINTIKOM (Jurnal Sains Manaj. Inform. dan Komputer), 2020, doi: 10.53513/jis.v19i1.231.

[6] D. Irmayani, "REKAYASA PERANGKAT LUNAK," J. Inform., 2019, doi: 10.36987/informatika.v2i3.201.

[7] M. Harry and L. Arpilian, "Belajar cepat metode SAW - Google Books," Kreatif, 2020. .

[8] "Software Prototyping: A Strategy to Use When User Lacks Data Processing Experience," ARPN J. Syst. Softw., 2012.

[9] D. Purnomo, "Model Prototyping Pada Pengembangan Sistem Informasi," J I M P - J. Inform. Merdeka Pasuruan, 2017, doi: 10.37438/jimp.v2i2.67.

[10] W. Nugraha and M. Syarif, "PENERAPAN METODE PROTOTYPE DALAM PERANCANGAN SISTEM INFORMASI PENGHITUNGAN VOLUME DAN COST PENJUALAN MINUMAN BERBASIS WEBSITE,” JUSIM (Jurnal Sist. Inf. Musirawas), 2018, doi: 10.32767/jusim.v3i2.331.

[11] B. McMillin, "Software Engineering," Computer. 2018, doi: 10.1109/MC.2018.1451647.

[12] A. Setiadi, Y. Yunita, and A. R. Ningsih, "Penerapan Metode Simple Additive Weighting(SAW) Untuk Pemilihan Siswa Terbaik," J. Sisfokom (Sistem Inf. dan Komputer), 2018, doi: 10.32736/sisfokom.v7i2.572. 